\title{
Sex differences in circulating proteins in heart failure with preserved ejection fraction
}

Susan Stienen ${ }^{1 *}$ D, João Pedro Ferreira ${ }^{1,2}$, Masatake Kobayashi ${ }^{1}$, Gregoire Preud'homme $^{1}$, Daniela Dobre ${ }^{1,3}$, Jean-Loup Machu' ${ }^{1}$, Kevin Duarte', Emmanuel Bresso ${ }^{4}$, Marie-Dominique Devignes ${ }^{4}$, Natalia López Andrés ${ }^{5}$, Nicolas Girerd ${ }^{1}$, Svend Aakhus ${ }^{6,7}$, Giuseppe Ambrosio ${ }^{8}$, Hans-Peter Brunner-La Rocca ${ }^{9}$, Ricardo Fontes-Carvalho ${ }^{10}$, Alan G. Fraser ${ }^{11}$, Loek van Heerebeek ${ }^{12}$, Gilles de Keulenaer ${ }^{13}$, Paolo Marino ${ }^{14}$, Kenneth McDonald ${ }^{15}$, Alexandre Mebazaa ${ }^{16}$, Zoltàn Papp ${ }^{17}$, Riccardo Raddino ${ }^{18}$, Carsten Tschöpe $^{19}$, Walter J. Paulus ${ }^{20}$, Faiez Zannad ${ }^{1 \dagger}$ and Patrick Rossignol ${ }^{1 \dagger}$

\section{Abstract}

Background: Many patients with heart failure with preserved ejection fraction (HFpEF) are women. Exploring mechanisms underlying the sex differences may improve our understanding of the pathophysiology of HFpEF. Studies focusing on sex differences in circulating proteins in HFpEF patients are scarce.

Methods: A total of 415 proteins were analyzed in $392 \mathrm{HFpEF}$ patients included in The Metabolic Road to Diastolic Heart Failure: Diastolic Heart Failure study (MEDIA-DHF). Sex differences in these proteins were assessed using adjusted logistic regression analyses. The associations between candidate proteins and cardiovascular (CV) death or CV hospitalization (with sex interaction) were assessed using Cox regression models.

Results: We found 9 proteins to be differentially expressed between female and male patients. Women expressed more LPL and PLIN1, which are markers of lipid metabolism; more LHB, IGFBP3, and IL1RL2 as markers of transcriptional regulation; and more Ep-CAM as marker of hemostasis. Women expressed less MMP-3, which is a marker associated with extracellular matrix organization; less NRP1, which is associated with developmental processes; and less ACE2, which is related to metabolism. Sex was not associated with the study outcomes (adj. HR $1.48,95 \% \mathrm{Cl} 0.83-2.63), p=0.18$.

Conclusion: In chronic HFpEF, assessing sex differences in a wide range of circulating proteins led to the identification of 9 proteins that were differentially expressed between female and male patients. These findings may help further investigations into potential pathophysiological processes contributing to HFpEF.

\footnotetext{
* Correspondence: s.stienen@amc.uva.nl

${ }^{\dagger}$ Faiez Zannad and Patrick Rossignol contributed equally to this work.

'Université de Lorraine, INSERM, Centre d'Investigation Clinique et

Plurithématique 1433, INSERM U1116, CHRU de Nancy, F-CRIN INI-CRCT

(Cardiovascular and Renal Clinical Trialists), Nancy, France

Full list of author information is available at the end of the article
}

(c) The Author(s). 2020 Open Access This article is licensed under a Creative Commons Attribution 4.0 International License, which permits use, sharing, adaptation, distribution and reproduction in any medium or format, as long as you give appropriate credit to the original author(s) and the source, provide a link to the Creative Commons licence, and indicate if changes were made. The images or other third party material in this article are included in the article's Creative Commons licence, unless indicated otherwise in a credit line to the material. If material is not included in the article's Creative Commons licence and your intended use is not permitted by statutory regulation or exceeds the permitted use, you will need to obtain permission directly from the copyright holder. To view a copy of this licence, visit http://creativecommons.org/licenses/by/4.0/ The Creative Commons Public Domain Dedication waiver (http://creativecommons.org/publicdomain/zero/1.0/) applies to the data made available in this article, unless otherwise stated in a credit line to the data. 


\section{Introduction}

Heart failure with preserved ejection fraction (HFpEF) presents an important challenge for clinical practice given its rising incidence, poor prognosis, and lack of clear evidence from randomized clinical trials of treatment that can reduce mortality [1-4]. Consistent epidemiological data demonstrate that women constitute the majority of patients with $\mathrm{HFpEF}$ [5]. Although to some extent explained by sex differences in cardiovascular structure and function, immune system biology, and the myocardial response to comorbidities [6], the underlying pathophysiological mechanisms of HFpEF remain incompletely understood.

Given the sex differences in HFpEF, we sought differences in biomarker profiles possibly linked to underlying pathophysiology. In this study, we therefore assessed sex differences in 415 circulating proteins in a prospective observational cohort of HFpEF patients (The Metabolic Road to Diastolic Heart Failure (MEDIA-DHF) study; NCT02446327).

\section{Methods}

\section{Study population}

In MEDIA-DHF, a multicenter, multinational, observational study, a total of $626 \mathrm{HFpEF}$ patients were enrolled between 2012 and 2014 in 10 centers (listed in Supplemental table 1). A description of this study population and methods has been published previously [7]. To summarize, after standardized echocardiography (Supplemental data) and/or local natriuretic peptide measurements, eligible patients with a diagnosis of diastolic dysfunction as established by the 2007 ESC recommendations [8] were included. Three clinical modes of presentations were considered: (i) acute decompensated HF patients, (ii) patients recently discharged after admission for an acute HF episode (< 60 days), or (iii) ambulatory chronic disease patients. Data on demographics, clinical parameters, laboratory values (including extensive biomarker measurements), electrocardiography, and echocardiography were obtained at inclusion in the study. Followup visits took place at 3,6 , and 12 months after inclusion in the study.

Only patients in whom the circulating proteins were measured were included in this substudy $(N=392$; see also flowchart in Supplemental figure 1). No protein measurements were performed in acute decompensated HF patients.

\section{Biomarker measurements}

Plasma samples taken at inclusion in the study were analyzed for circulating protein (including natriuretic peptides) using the Olink Proseek Multiplex cardiovascular disease (CVD) II, III, inflammation, cardiometabolic, and organ damage panels (Olink Proteomics, Uppsala,
Sweden). The assay uses a proximity extension assay (PEA) technology where 92 oligonucleotide-labeled antibody probe pairs per panel are allowed to bind to their respective targets in $1 \mu \mathrm{L}$ plasma sample. The PEA technology has been described previously [9]. In brief, when binding to their correct targets, they give rise to new DNA amplicons with each ID barcoding their respective antigens. The amplicons are subsequently quantified using a Fluidigm BioMark HD real-time PCR platform. Data is quality controlled and normalized using an internal extension control and an inter-plate control, to adjust for intra- and inter-run variation. The extension control is composed of an antibody coupled to a unique pair of DNA-tags that serves as a synthetic control that is added to every sample well. It will adjust for technical variation introduced in the extension step and hence reduce intra-assay variability. The final assay read-out is presented in log2-normalized protein expression (NPX) data where an increase of 1 NPX confers a doubling in concentration of the specific biomarker. This arbitrary unit is therefore a relative quantification of proteins and compares fold changes between groups. All assay validation data for the proteins in the cardiovascular II, cardiovascular III, inflammation, cardiometabolic, and organ damage panels (detection limits, intra- and interassay precision data, accuracy, etc.) are available on the manufacturer's website (www. olink.com). We excluded proteins that were below the lower limit of detection in more than $50 \%$ of the patients $(N=45)$. For the proteins below the LOD in less than $50 \%$ of patients, the LOD value was imputed. A total of 415 protein circulating proteins were studied. The abbreviations, full names, and respective Olink multiplex panels of all measured proteins are described in the Supplemental table 2.

\section{Clinical outcome}

The pre-specified endpoint of MEDIA-DHF was a composite of CV death and/or CV hospitalizations (NCT02446327). All endpoints were adjudicated by an independent endpoint committee blinded to the biomarker data.

\section{Network analyses}

The FHF-GKB (Fight Heart Failure-Graph Knowledge Box) resource is a customized upgrade of the EdgeBox provided by the EdgeLeap company (available from: https://www.edgeleap.com/edgebox). It extracts data from public data sources hence providing most available public knowledge about human protein-disease, protein-protein, and protein-pathway relationships. The FHF-GKB resource enables the study of a total of 20,386 protein nodes imported from UniProt [10] (including all circulating proteins involved in this study), 28,176 disease nodes from Disease Ontology [11] and DisGenet [12], and 2222 pathway nodes from Reactome (v65) [13]. Protein-protein 
relationships were retrieved from STRING (v10.5) [14], or Reactome or WikiPathways [15], or Mentha [16], or BioGrid [17], protein-disease associations from DisGenet (2018-08-24), and protein-pathway relationships from Reactome.

\section{Statistical analyses}

Baseline clinical, demographic, and echocardiographic characteristics were compared between male and female patients using chi-square, $t$ test, or Mann-Whitney tests, as appropriate.

To study whether biomarker patterns differ between male and female patients, we first identified which clinical variables were associated with female sex using logistic regression analysis ("clinical model"). All variables listed in Table 1 were considered in univariate analyses, apart from dyslipidemia as a diagnosis, hemoglobin as a continuous variable, NT-proBNP, and use of aspirin. Variables with $\geq 20 \%$ missing values were excluded from further analyses (pulmonary artery pressure (PASP), left atrial area, ratio of the early (E) to late $(\mathrm{A})$ ventricular filling velocities (E/A), waist circumference, sodium, potassium, and CRP). Anemia was defined as hemoglobin $<12 \mathrm{~g} / \mathrm{dL}$ in women and $<13 \mathrm{~g} / \mathrm{dL}$ in men, according to the World Health Organization recommendations.

Missing predictor values with $<20 \%$ of missing values were imputed using linear regression analyses (see Table 1 for the percentage of missing data for each variable). We imputed missing data 10 times, performed the analysis over all the 10 imputations, and averaged results using Rubin's rules [18]. Log-linearity of continuous variables was assessed visually by inspecting the shape of the distribution of the beta-estimates vs. the median by quintiles with regard to the outcome of interest ("female sex"). If deemed appropriate based on log-linearity, continuous variables were categorized. Variables with significant $p$ values $(<0.05)$ in univariate analyses were considered in the multivariate model. The discrimination of the final multivariate model for estimation of clinical end-points was assessed by calculating the area under the curve (AUC). Similar beta-estimates of variables in the multivariate model derived from the multiple imputation datasets were obtained when the pooled mean hemoglobin $(N=46)$, heart rate $(N=12)$, and total cholesterol levels $(N=67)$ were imputed in the original datasets (data not shown). Further analyses were therefore performed in the original dataset with pooled mean levels for hemoglobin, heart rate, and total cholesterol.

To identify differences in proteins between sexes, we studied which proteins were significantly associated with female sex on top of the clinical model. Therefore, all proteins were tested individually on top of the clinical model (i.e., fully adjusted on the clinical variables) in a bivariate logistic regression model, correcting for multiple comparisons using a Bonferroni adjusted $p$ value of $<0.00012$ (alpha divided by 415 proteins). We subsequently searched for correlated proteins $(>0.3)$. In order to ascertain independence, we excluded the protein with the largest mean absolute correlation from the two correlated proteins. An additional analysis excluding proteins correlated $>0.5$ was performed.

The FHF-GKB complex network was queried in order to explore pathways and proteins that could connect together biomarker (BM) nodes of interest. Queries were expressed according to query patterns defining a path structure between two nodes such as BM-BM, BMpathway- $\mathrm{BM}$, and $\mathrm{BM}$-protein-BM, where the BM nodes are taken from a list of interest. The resulting graphs were merged in a figure illustrating all possible paths not longer than two edges, connecting proteins through pathways and proteins.

The association between sex and the composite endpoint of $\mathrm{CV}$ death or $\mathrm{CV}$ hospitalizations within 1 year after inclusion in the study was studied using KaplanMeier estimates and Cox proportional hazards models. In multivariate analyses, adjustment was performed for clinical variables previously found to be independently associated with $\mathrm{CV}$ death or $\mathrm{CV}$ hospitalizations in MEDIA-DHF [7]. These clinical variables were a history of CAD, pulmonary rales at baseline, and age. The proportional hazard assumption was not met, and a landmark analysis was performed excluding those patients with an endpoint or being censored within 120 days after inclusion in the study.

Statistical analyses were performed using SPSS 24 (IBM Inc., Armonk, NY) and R (The R Foundation for Statistical Computing, Vienna, Austria). This is the first report on sex differences in clinical features, circulating proteins and outcome in MEDIA-DHF.

\section{Results \\ Baseline characteristics}

There were more female than male patients included in MEDIA-DHF ( $64 \%$ vs. $36 \%, p<0.001)$. The distribution of demographic, clinical, and laboratory variables according to sex is summarized in Table 1. Female patients were older by an average of 2 years, had lower hemoglobin levels (by 4.5\%), and a higher heart rate (by $3 \mathrm{bpm}$ ) and total cholesterol (by $120 \mathrm{mg} / \mathrm{dL}$ ) when compared to male patients. Male patients were more often current smokers and more likely to have a history of diabetes mellitus, CAD, peripheral arterial disease, and prior hospitalizations for HF. Echocardiographic variables are listed in Table 2.

\section{Clinical model: variables associated with female sex}

Baseline clinical variables that were independently associated with female sex are depicted in Table 3. These 
Table 1 Baseline characteristics of patients in the MEDIA-DHF cohort according to sex

\begin{tabular}{|c|c|c|c|c|c|}
\hline & Global $(\boldsymbol{N}=392)$ & Male $(\boldsymbol{N}=142)$ & Female $(\boldsymbol{N}=250)$ & $\boldsymbol{p}$ value & $\%$ of missing values \\
\hline Age, years, median (IQR) & $74.0(67.5-80.0)$ & $73.0(67.0-79.0)$ & $75.0(68.0-81.0)$ & 0.028 & 0 \\
\hline Recently decompensated HF, $n(\%)$ & $60(15.3 \%)$ & $25(17.6 \%)$ & 35 (14.0\%) & 0.34 & 0 \\
\hline \multicolumn{6}{|l|}{ Smoking status, $n(\%)$} \\
\hline Never & $205(52.7 \%)$ & 39 (27.9\%) & $166(66.7 \%)$ & $<0.001$ & 1 \\
\hline Former & $150(38.6 \%)$ & $84(60.0 \%)$ & $66(26.5 \%)$ & & \\
\hline Current & $34(8.7 \%)$ & $17(12.1 \%)$ & $17(6.8 \%)$ & & \\
\hline $\mathrm{BMl}, \mathrm{kg} / \mathrm{m}^{2}$, mean $\pm \mathrm{SD}$ & $30.6 \pm 6.2$ & $30.5 \pm 5.6$ & $30.6 \pm 6.5$ & 0.79 & 1 \\
\hline \multicolumn{6}{|l|}{ Alcohol status, $n(\%)$} \\
\hline Non-consumer & $245(63.3 \%)$ & $73(52.1 \%)$ & $172(69.6 \%)$ & 0.001 & 1 \\
\hline $1-2$ drinks/day & $124(32.0 \%)$ & $56(40.0 \%)$ & $68(27.5 \%)$ & & \\
\hline$>2$ drinks/day & $18(4.7 \%)$ & $11(7.9 \%)$ & $7(2.8 \%)$ & & \\
\hline Waist circumference, $\mathrm{cm}$, mean $\pm \mathrm{SD}$ & $104.8 \pm 14.1$ & $108.2 \pm 13.8$ & $102.9 \pm 13.9$ & 0.001 & 21 \\
\hline $\mathrm{SBP}, \mathrm{mmHg}$, mean $\pm \mathrm{SD}$ & $137.2 \pm 23.1$ & $137.5 \pm 22.3$ & $137.0 \pm 23.5$ & 0.83 & 2 \\
\hline $\mathrm{DBP}, \mathrm{mmHg}$, mean $\pm \mathrm{SD}$ & $74.0 \pm 11.6$ & $74.7 \pm 11.1$ & $73.7 \pm 11.9$ & 0.41 & 2 \\
\hline Pulmonary rales, $n(\%)$ & 89 (23.0\%) & $33(23.4 \%)$ & $56(22.8 \%)$ & 0.89 & 1 \\
\hline NYHA class III/IV, n (\%) & $73(18.7 \%)$ & $23(16.2 \%)$ & $50(20.1 \%)$ & 0.34 & 0 \\
\hline Peripheral edema, $n(\%)$ & $178(45.4 \%)$ & $74(52.1 \%)$ & $104(41.6 \%)$ & 0.045 & 1 \\
\hline Elevated JVP, $n(\%)$ & $24(6.3 \%)$ & $12(8.7 \%)$ & $12(4.9 \%)$ & 0.15 & 3 \\
\hline Hepatomegaly, $n$ (\%) & $13(3.6 \%)$ & $6(4.5 \%)$ & $7(3.1 \%)$ & 0.68 & 7 \\
\hline Fatigue at exertion, $n(\%)$ & $305(79.2 \%)$ & $105(75.5 \%)$ & $200(81.3 \%)$ & 0.18 & 2 \\
\hline Heart rate, bpm, mean \pm SD & $69.4 \pm 14.4$ & $67.1 \pm 12.9$ & $70.8 \pm 15.0$ & 0.016 & 3 \\
\hline Hypertension, n (\%) & $342(87.7 \%)$ & $121(86.4 \%)$ & $221(88.4 \%)$ & 0.57 & 1 \\
\hline Atrial fibrillation, $n(\%)$ & 117 (31\%) & $49(36 \%)$ & $68(28 \%)$ & 0.13 & 3 \\
\hline Diabetes mellitus, $n(\%)$ & $154(39.3 \%)$ & $67(47.2 \%)$ & 87 (34.8\%) & 0.016 & 0 \\
\hline Dyslipidemia, n (\%) & $226(58.2 \%)$ & $75(53.6 \%)$ & $151(60.9 \%)$ & 0.16 & 1 \\
\hline Previous HF hospitalization, $n(\%)$ & $137(35.5 \%)$ & 65 (46.8\%) & $72(29.1 \%)$ & $<0.001$ & 2 \\
\hline$C A D, n(\%)$ & $128(33.7 \%)$ & 73 (52.9\%) & $55(22.7 \%)$ & $<0.001$ & 3 \\
\hline Stroke or TIA, $n(\%)$ & $44(11.3 \%)$ & $14(10.0 \%)$ & $30(12.0 \%)$ & 0.54 & 1 \\
\hline Peripheral artery disease, $n$ (\%) & $34(8.9 \%)$ & $18(13.0 \%)$ & $16(6.5 \%)$ & 0.030 & 2 \\
\hline COPD, $n(\%)$ & $71(18.4 \%)$ & $30(21.4 \%)$ & $41(16.7 \%)$ & 0.25 & 2 \\
\hline \multicolumn{6}{|l|}{ Laboratory values, mean \pm SD } \\
\hline $\mathrm{LDL}, \mathrm{mg} / \mathrm{dL}$ & $99.8 \pm 37.1$ & $89.8 \pm 30.2$ & $104.5 \pm 39.1$ & $<0.001$ & 20 \\
\hline $\mathrm{HDL}, \mathrm{mg} / \mathrm{dL}$ & $53.7 \pm 19.7$ & $47.3 \pm 15.5$ & $56.8 \pm 20.8$ & $<0.001$ & 19 \\
\hline Total cholesterol, mg/dL & $176.1 \pm 43.1$ & $160.2 \pm 35.1$ & $183.9 \pm 44.6$ & $<0.001$ & 17 \\
\hline Hemoglobin, g/dL & $13.0 \pm 1.6$ & $13.4 \pm 1.8$ & $12.8 \pm 1.5$ & $<0.001$ & 12 \\
\hline Anemia, $n(\%)$ & $106(30.6 \%)$ & $46(39.0 \%)$ & $60(26.3 \%)$ & 0.019 & 12 \\
\hline $\mathrm{eGFR}, \mathrm{mL} / \mathrm{min} / 1.73 \mathrm{~m}^{2}$ & $66.4 \pm 23.1$ & $66.4 \pm 23.7$ & $66.4 \pm 22.8$ & 1.00 & 6 \\
\hline NT-proBNP (in NPX) & $4.2 \pm 1.3$ & $4.4 \pm 1.4$ & $4.1 \pm 1.3$ & 0.042 & 0 \\
\hline \multicolumn{6}{|l|}{ Medication prescription rates, $n(\%)$} \\
\hline ACEi or ARB & $319(81.4 \%)$ & $114(80.3 \%)$ & 205 (82.0\%) & 0.67 & 0 \\
\hline Beta blockers & $286(73.0 \%)$ & $111(78.2 \%)$ & $175(70.0 \%)$ & 0.080 & 0 \\
\hline Thiazide diuretics & $87(22.3 \%)$ & $22(15.5 \%)$ & $65(26.1 \%)$ & 0.015 & 0 \\
\hline Loop diuretics & $235(59.9 \%)$ & 89 (62.7\%) & $146(58.4 \%)$ & 0.41 & 0 \\
\hline MRA & $43(11.0 \%)$ & $16(11.3 \%)$ & $27(10.8 \%)$ & 0.87 & 0 \\
\hline
\end{tabular}


Table 1 Baseline characteristics of patients in the MEDIA-DHF cohort according to sex (Continued)

\begin{tabular}{llllll}
\hline & Global $(\boldsymbol{N}=392)$ & Male $(\boldsymbol{N}=142)$ & Female $(\boldsymbol{N}=250)$ & $\boldsymbol{p}$ value & \% of missing values \\
\hline Aspirin & $159(40.6 \%)$ & $64(45.1 \%)$ & $95(38.0 \%)$ & 0.17 & 0 \\
Insulin & $52(13.3 \%)$ & $26(18.3 \%)$ & $26(10.4 \%)$ & 0.028 & 0 \\
Statin & $241(61.5 \%)$ & $96(67.6 \%)$ & $145(58.0 \%)$ & 0.060 & 0 \\
Oral anticoagulants & $161(41.1 \%)$ & $57(40.1 \%)$ & $104(41.6 \%)$ & 0.78 & 0 \\
\hline
\end{tabular}

Legend: $H F$ heart failure, $B M I$ body mass index, $D M$ diabetes mellitus, $C A D$ coronary artery disease, $P A D$ peripheral artery disease, COPD chronic obstructive pulmonary disease, OSAS obstructive sleep apnea syndrome, TIA transient ischemic attack, DBP diastolic blood pressure, SBP systolic blood pressure, NYHA New York Heart Association, JVP jugular venous pressure, eGFR estimated glomerular filtration rate, $B N P$ brain natriuretic peptide, NT-proBNP N-terminal pro-brain natriuretic peptide, NPX normalized protein expression, $A S A$ acetylsalicylic acid, $A C E i$ ACE-inhibitor, $A R B$ angiotensin receptor blocker, $B B$ beta blocker, $M R A$ mineralocorticoid receptor antagonist, $L V E F$ left ventricular ejection fraction, $E / e^{\prime}$ the ratio of mitral inflow velocity and early mitral annulus velocity, $P A S P$ pulmonary artery systolic pressure, TAPSE tricuspidal annular plane systolic excursion, E/A ratio of the early (E) to late (A) ventricular filling velocities, LVEDVi left ventricular end-diastolic volume index, LVESVi left ventricular end-systolic volume index, LAVI left atrial volume index, IQR interquartile range, SD standard deviation

variables were higher heart rate, higher total cholesterol, lower hemoglobin, no CAD, no prior HF hospitalizations, and no history of smoking.

\section{Association between circulating proteins and female sex} For all individual proteins (including NT-proBNP), associations with female sex were assessed. A total of 17 were identified of which 9 proteins were not correlated $(r<0.3)$ with other proteins. Of these 9 proteins, 6 were positively associated with female sex (insulin-like growth factorbinding protein 3 (IGFBP3), interleukin-1 receptor-like 2 (IL1RL2), lipoprotein lipase (LPL), epithelial cell adhesion molecule (Ep-CAM), perilipin-1 (PLIN1), and lutropin subunit beta (LHB)) and 3 were negatively associated (neuropilin-1 (NRP1), matrix metalloproteinase-3 (MMP-3), angiotensin-converting enzyme 2 (ACE2)) with female sex (Table 3; Supplemental Table 2). Proteins with moderate correlations $(r<0.5)$ are shown in Supplemental Table 3.

\section{Network analyses}

The visualization of the interactions between circulating proteins and pathways is depicted in the Fig. 1. The 6 proteins that were higher expressed in female vs. male patients were linked to pathways involved in lipid metabolism, transcriptional regulation, and hemostasis. The proteins that were higher expressed in male vs. female patients pointed to pathways related to extracellular matrix organization and developmental processes. Common pathways between the "female" and "male" proteins were signal transduction cascades, protein metabolism, and cytokine signaling.

\section{Outcome}

There was no difference in the rates of the composite endpoint of CV death or CV hospitalization between female and male patients after 1 year of follow-up (event rates $41 / 250$ (16.4\%) female patients vs. 19/142 (13.4\%) male patients, log rank test: $p=0.46$; Fig. 2). Crude and adjusted hazard ratios for the composite endpoint are depicted in Table 4 (adjusted HR 1.48, 95\% CI 0.832.63, $p=0.18)$.

\section{Discussion}

In this study, we investigated sex differences in circulating proteins measured in a cohort of 392 HFpEF patients. From over 400 proteins measured, we found 9 proteins to be significantly and independently associated with female sex and HFpEF. Females expressed more IGFBP3, IL1RL2, LPL, Ep-CAM, PLIN1, and LHB which are markers of lipid metabolism, transcriptional

Table 2 Echocardiography characteristics of patients in the MEDIA-DHF cohort according to sex

\begin{tabular}{|c|c|c|c|c|c|}
\hline Echocardiographic variables, mean \pm SD & Global $(\boldsymbol{N}=392)$ & Male $(\boldsymbol{N}=142)$ & Female $(\boldsymbol{N}=250)$ & $\boldsymbol{p}$ value & $\%$ of missing values \\
\hline LVEF, \% & $60.8 \pm 7.0$ & $60.5 \pm 6.9$ & $61.0 \pm 7.0$ & 0.54 & 0 \\
\hline$E / e^{\prime}$ & $13.3 \pm 5.2$ & $12.6 \pm 4.6$ & $13.7 \pm 5.4$ & 0.057 & 7 \\
\hline PASP, $\mathrm{mmHg}$ & $34.8 \pm 12.7$ & $34.9 \pm 15.0$ & $34.8 \pm 11.4$ & 0.97 & 25 \\
\hline TAPSE, cm & $20.5 \pm 4.8$ & $21.0 \pm 5.4$ & $20.2 \pm 4.4$ & 0.13 & 10 \\
\hline E/A & $1.3 \pm 0.9$ & $1.4 \pm 1.0$ & $1.2 \pm 0.8$ & 0.033 & 30 \\
\hline LDEVi & $43.8 \pm 14.0$ & $48.3 \pm 14.4$ & $41.1 \pm 13.1$ & $<0.001$ & 4 \\
\hline LDESi & $17.4 \pm 7.3$ & $19.6 \pm 7.5$ & $16.2 \pm 6.7$ & $<0.001$ & 6 \\
\hline $\mathrm{LAVI}, \mathrm{ml} / \mathrm{m}^{2}$ & $43.8 \pm 15.8$ & $45.0 \pm 16.6$ & $43.1 \pm 15.4$ & 0.27 & 3 \\
\hline
\end{tabular}

Legend: $L V E F$ left ventricular ejection fraction, $E / e^{\prime}$ the ratio of mitral inflow velocity and early mitral annulus velocity, $P A S P$ pulmonary artery systolic pressure, TAPSE tricuspidal annular plane systolic excursion, $E / A$ ratio of the early $(E)$ to late $(A)$ ventricular filling velocities, $L V E D V i$ left ventricular end-diastolic volume index, LVESVi left ventricular end-systolic volume index, LAVI left atrial volume index, IQR interquartile range, SD standard deviation 
Table 3 Adjusted and multiple testing-corrected circulating proteins associated with female sex

\begin{tabular}{|c|c|c|c|c|}
\hline & \multicolumn{2}{|l|}{ Clinical model (AUC 0.82) } & \multicolumn{2}{|l|}{ Proteins } \\
\hline & OR (95\% Cl) for female sex association & $p$ value & OR $(95 \% \mathrm{Cl})$ for female sex association & $p$ value \\
\hline Heart rate, per $10 \mathrm{bpm}$ increase & $1.22(1.00-1.48)$ & 0.049 & & \\
\hline Total cholesterol, per $10 \mathrm{mg} / \mathrm{dL}$ increase & $1.13(1.03-1.02)$ & 0.010 & & \\
\hline \multicolumn{5}{|l|}{ Smoking status } \\
\hline Never & Ref. & - & & \\
\hline Former & $0.21(0.12-0.36)$ & $<0.001$ & & \\
\hline Current & $0.33(0.14-0.80)$ & 0.014 & & \\
\hline CAD & $0.36(0.21-0.62)$ & $<0.001$ & & \\
\hline Previous HF hospitalization & $0.47(0.27-0.82)$ & 0.008 & & \\
\hline $\mathrm{Hb}$, per $1 \mathrm{~g} / \mathrm{dL}$ increase & $0.69(0.57-0.82)$ & $<0.001$ & & \\
\hline \multicolumn{5}{|l|}{ Higher expression in females vs. males } \\
\hline IL1RL2 & & & $4.13(2.22-7.68)$ & $<0.001$ \\
\hline LPL & & & $4.08(2.44-6.82)$ & $<0.001$ \\
\hline LHB & & & $3.15(2.20-4.52)$ & $<0.001$ \\
\hline IGFBP3 & & & $2.83(1.74-4.58)$ & $<0.001$ \\
\hline PLIN1 & & & $2.44(1.62-3.66)$ & $<0.001$ \\
\hline Ep-CAM & & & $1.87(1.41-2.48)$ & $<0.001$ \\
\hline \multicolumn{5}{|l|}{ Less expression in females vs. males } \\
\hline NRP1 & & & $0.05(0.01-0.19)$ & $<0.001$ \\
\hline MMP-3 & & & $0.22(0.14-0.35)$ & $<0.001$ \\
\hline ACE2 & & & $0.41(0.28-0.61)$ & $<0.001$ \\
\hline
\end{tabular}

Each OR unit increase represents doubling in the NPX values

Legend: eGFR estimated glomerular filtration rate, $O R$ odds ratio, $C l$ confidence interval, $A U C$ area under the curve, bpm beats per minute, CAD coronary artery disease, $H F$ heart failure, $H b$ hemoglobin, IGFBP3 insulin-like growth factor-binding protein 3, NRP1 neuropilin 1, IL1RL2 interleukin-1 receptor-like 2, LPL lipoprotein lipase, ACE2 angiotensin-converting enzyme 2, Ep_CAM epithelial cell adhesion molecule, CA14 carbonic anhydrase 14, PLIN1 perilipin-1, LHB lutropin subunit beta

regulation, and hemostasis, whereas they expressed less NRP1, MMP-3, and ACE2 which are markers associated with extracellular matrix organization and developmental processes.

\section{Sex differences: clinical features}

We found several clinical variables associated with female subjects with HFpEF: higher heart rate, higher total cholesterol, lower hemoglobin, absence of CAD, no prior HF hospitalizations, and not smoking. These findings are in agreement with previous studies $[6,19,20]$. Although previously shown for acute HF patients [21], an association between female sex and higher cholesterol levels in HFpEF has thus far not been reported. Although females were slightly older than male subjects, there was no significant association between age and female sex in this cohort. Interestingly, females were $14 \%$ less likely to receive statin therapy at baseline in MEDIA-DHF compared to males. A possible explanation for the higher total cholesterol levels but lower rates of CAD in females compared to males may be that females tend to have microvascular lesions and endothelial dysfunction, whereas males are more likely to have obstructive coronary lesions [22], which may potentially lead to an underdiagnosis of coronary artery disease in females.

\section{Sex differences: circulating proteins}

In this study, plasma levels of 9 proteins were significantly differentially expressed between female and male patients. Of these 9 proteins, 6 were higher expressed in female compared to male patients (IGFBP3, IL1RL2, LPL, Ep-CAM, PLIN1, and LHB), whereas the other 3 proteins were higher expressed in males (NRP1, ACE2, and MMP-3). Network analysis revealed that the proteins that were higher expressed in female vs. male patients may be linked to pathways involved in lipid metabolism, transcriptional regulation, and hemostasis. The proteins that were higher expressed in males vs. females pointed more towards pathways involved in extracellular matrix organization and developmental processes. Common pathways were signal transduction cascades, protein metabolism, and cytokine signaling.

Proposed mechanistic actions and previous studies investigating the differently expressed circulating proteins in HFpEF are described next and summarized in Table 5. IGFBP3 is the most abundant carrier protein for insulin- 

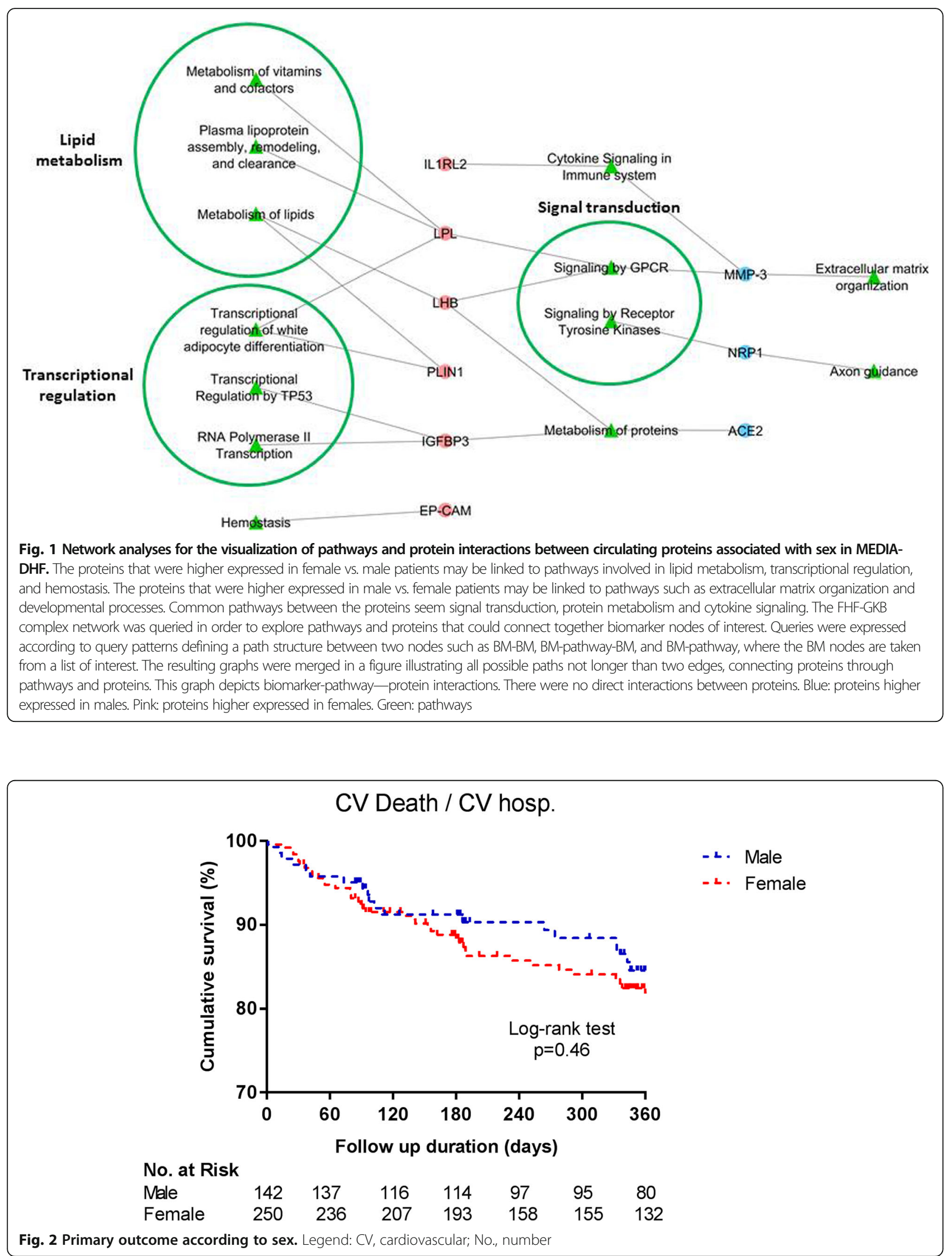
Table 4 Crude and adjusted hazard ratios for the prediction of cardiovascular death and/or cardiovascular hospitalization during 1 year of follow-up according to sex

\begin{tabular}{llr}
\hline & Crude HR (95\% Cl) & Adj. HR (95\% Cl)* \\
\hline Complete cohort & $1.26(0.73-2.16), p=0.41$ & $1.48(0.83-2.63), p=0.18$ \\
$\quad$ Female vs. male & $1.70(0.72-4.03), p=0.23$ & $1.89(0.77-4.65), p=0.17$ \\
$\begin{array}{l}\text { Landmark analysis (> } 120 \text { days) } \\
\quad \text { Female vs. male }\end{array}$
\end{tabular}

The proportional hazard assumption was not met, and a landmark analysis was performed excluding those patients with an endpoint or being censored within 120 days after inclusion in the study

*Adjusted on coronary artery disease, pulmonary rales at baseline, and age. Since our aim was to assess the association of female sex on top of this clinical risk score and female sex was already incorporated in the prognostic risk score, sex was not considered in the prognostic risk score used for these analyses

like growth factor 1 (IGF-1) which is known to regulate proliferation, differentiation, metabolism, and cell survival in various tissues. It has been linked to hypertension, obesity, cardiovascular disease, and many cancers [27, 28]. After an acute myocardial infarction, IGFBP-3 and IGF-1 levels significantly increased, which was associated with improved outcomes and echocardiographic parameters (LV dimensions, mass and ejection fraction) [30]. A recent study in $84 \mathrm{HFpEF}$ patients demonstrated a high prevalence of anabolic hormonal deficiencies (including IGF-1), and low IGF-1 serum levels were associated with increased left atrial size and volume [29]. Although IGFBP-3 levels were numerically higher in female compared to male participants in the Cardiovascular Health Study [31], to our knowledge, there have been no reports, so far, on sex differences in HFpEF or other cardiovascular diseases.

IL1RL2 (or IL-36 receptor) activates pro-inflammatory pathways upon binding to IL-36 [23]. Accumulating data indicates that IL1RL2 is involved in inflammatory diseases such as psoriasis, inflammatory bowel disease, and rheumatoid arthritis [23]. No previous studies have reported on IL1RL2 in HFpEF or other cardiovascular disease.

The transmembrane glycoprotein expressed in epithelium, Ep-CAM, is involved in various processes such as cell signaling, cell-cell adhesion, proliferation and differentiation, tumorigenesis, and metastasis of carcinomas and has been associated with inflammatory bowel disease [35]. Ep-CAM was not associated with adverse cardiovascular outcomes in a registry of 263 chronic heart failure patients [36]. To our knowledge, no studies have investigated sex differences in Ep-CAM, in healthy subjects or in patients.

LPL is an enzyme widely expressed in the heart which catalyzes the hydrolysis of triglyceride-rich lipoproteins to fatty acids, as fuel for cardiomyocyte metabolism [46]. It plays an important role in atherogenesis and has been associated with coronary heart disease, Alzheimer's disease, and chronic lymphocytic leukemia [25]. LPL deficiency leads to hypertriglyceridemia [47], whereas overexpression of LPL in a mice model resulted in insulin resistance and obesity [48, 49]. Influencing cardiac
LPL in diabetic mouse models (by either overexpression or downregulation) resulted in impaired cardiac function [24].

Another enzyme involved in lipid metabolism is PLIN1 which is a surface protein of adipocyte lipid droplets that regulates storage and hydrolysis of adipose triglycerides. It has been associated with metabolic diseases such as diabetes, obesity, hepatic steatosis, certain cancers, and cardiovascular disease [33]. Downregulation of PLIN1 in mice led to excessive cardiac hypertrophy and failure [50]. A previous study demonstrated that PLIN1, as a marker of myocardial steatosis, was higher expressed in the right atria of patients with CAD compared to those without [34].

LHB (the beta subunit of luteinizing hormone) promotes spermatogenesis and ovulation by stimulating the testes and ovaries to synthesize steroids. A previous study measured LH in men and postmenopausal women with CAD but also in controls and demonstrated that LH levels were higher in females compared to males but that there was no difference between CAD and control subjects [26]. It is therefore possible that our finding of higher LHB levels in female compared to male HFpEF patients may be explained by higher LHB in females in general and that it may not be HFpEF-specific.

Proteins with higher expression in male compared to female HFpEF patients were NRP, ACE2, and MMP-3. NRP1 is a transmembrane receptor for class III semaphorins and for members of the vascular endothelial growth factor family [37]. It plays a role in neuronal and vascular development during embryogenesis, angiogenesis, and maintenance of vascular integrity [38]. In a murine model of cardiac pressure overload, animals that were heterozygous for neuropilin showed higher mortality rates [51]. Additionally, Tromp et al. demonstrated that NRP1 was associated with poor outcome in HFpEF but not in HFrEF patients [39].

ACE2 hydrolyses angiotensin I and angiotensin II generating angiotensin (1-9) and angiotensin (1-7), respectively. Both angiotensin (1-9) and angiotensin (1-7) are believed to possess direct protective effects against cardiac remodeling and it is hypothesized that the failing 
Table 5 Overview of the proteins differentially expressed between sexes

\begin{tabular}{|c|c|c|c|c|c|}
\hline \multirow{2}{*}{$\begin{array}{l}\text { Individual } \\
\text { biomarker }\end{array}$} & \multirow[t]{2}{*}{ Mechanistic significance } & \multicolumn{2}{|l|}{ Previous relevant reports } & \multicolumn{2}{|c|}{ Reports on sex differences } \\
\hline & & Basic reports & Clinical reports & Healthy population & Heart disease \\
\hline \multicolumn{6}{|c|}{ More highly expressed in females } \\
\hline IL1RL2 & $\begin{array}{l}\text { Activates pro-inflammatory } \\
\text { pathways upon binding of } \\
\text { IL-36 [23] }\end{array}$ & & $\begin{array}{l}\text { Involved in inflammatory diseases } \\
\text { such as psoriasis, inflammatory } \\
\text { bowel disease and rheumatoid } \\
\text { arthritis [23] }\end{array}$ & No & No \\
\hline LPL & $\begin{array}{l}\text { Enzyme that catalyzes the } \\
\text { hydrolysis of triglycerides }\end{array}$ & $\begin{array}{l}\text { Overexpression or } \\
\text { downregulation of cardiac LPL in } \\
\text { diabetic mouse models resulted } \\
\text { in impaired left ventricular } \\
\text { function [24]. }\end{array}$ & $\begin{array}{l}\text { Associated with coronary heart } \\
\text { disease, Alzheimer disease, and } \\
\text { chronic lymphocytic leukemia } \\
{[25]}\end{array}$ & No & No \\
\hline LHB & $\begin{array}{l}\text { Promotes spermatogenesis } \\
\text { and ovulation by } \\
\text { stimulating the testes and } \\
\text { ovaries to synthesize } \\
\text { steroids }\end{array}$ & & $\begin{array}{l}\text { Levels not different between } \\
\text { CAD and control subjects [26] }\end{array}$ & $\begin{array}{l}\text { Yes (higher in } \\
\text { females vs. males } \\
{[26] \text { ) }}\end{array}$ & $\begin{array}{l}\text { Yes (higher in } \\
\text { female vs. } \\
\text { male CAD } \\
\text { patients [26]) }\end{array}$ \\
\hline IGFBP3 & $\begin{array}{l}\text { Most abundant carrier } \\
\text { protein for insulin-like } \\
\text { growth factor } 1 \text { (IGF-1) } \\
\text { which is known to play a } \\
\text { major role in metabolism }\end{array}$ & $\begin{array}{l}\text { The IGF system (including } \\
\text { IGFBP3) has been previously } \\
\text { associated with cardiovascular } \\
\text { disease and many cancers [27, } \\
\text { 28] }\end{array}$ & $\begin{array}{l}\text { In HFpEF patients, low IGF-1 and } \\
\text { IGFBP3 were associated with in- } \\
\text { creased parameters of left atrial } \\
\text { size and volume [29]. } \\
\text { Higher IGF-1 after an acute MI } \\
\text { was associated with improved } \\
\text { clinical outcomes and echocar- } \\
\text { diographic measures (LV dimen- } \\
\text { sions, mass, and ejection fraction) } \\
\text { [30] }\end{array}$ & $\begin{array}{l}\text { Yes (numerically } \\
\text { higher in female vs. } \\
\text { male but no formal } \\
\text { comparison made } \\
\text { [31]) }\end{array}$ & No \\
\hline PLIN1 & $\begin{array}{l}\text { Surface protein of } \\
\text { adipocyte lipid droplets } \\
\text { that regulates storage and } \\
\text { hydrolysis of adipose } \\
\text { triglycerides [32] }\end{array}$ & $\begin{array}{l}\text { Linked to endocrine metabolism } \\
\text { disease (diabetes, obesity etc.), } \\
\text { cancers, and cardiovascular } \\
\text { disease [33] }\end{array}$ & $\begin{array}{l}\text { Higher expressed in the right } \\
\text { atria of patients with CAD } \\
\text { compared to those without [34] }\end{array}$ & No & No \\
\hline $\begin{array}{l}\text { Ep- } \\
\text { CAM }\end{array}$ & $\begin{array}{l}\text { Transmembrane } \\
\text { glycoprotein expressed in } \\
\text { epithelium }\end{array}$ & $\begin{array}{l}\text { Involved in various processes } \\
\text { such as cell signaling, cell-cell ad- } \\
\text { hesion, proliferation and differen- } \\
\text { tiation, tumorigenesis, and } \\
\text { metastasis of carcinomas [35] }\end{array}$ & $\begin{array}{l}\text { Not associated with adverse } \\
\text { cardiovascular outcomes in a } \\
\text { registry of } 263 \text { chronic heart } \\
\text { failure patients [36] } \\
\text { Associated with inflammatory } \\
\text { bowel disease [35] }\end{array}$ & No & No \\
\hline
\end{tabular}

Less expressed in females

NRP1 Transmembrane receptor for class III semaphorins and for members of the vascular endothelial growth factor family [37]

MMP-3 Enzyme involved in the breakdown of extracellular matrix proteins

ACE2 Hydrolyses angiotensin I and angiotensin II generating angiotensin (1-9) and angiotensin [1-5], respectively.
Neuronal and vascular development during embryogenesis, angiogenesis, and maintenance of vascular integrity [38]

Involved in physiological (e.g. embryogenesis) and pathophysiological (e.g. tumor metastasis and atherosclerosis) processes [40]
Associated with poor outcome in HFpEF but not in HFrEF patients [39]

Conflicting data: high levels have been described in atherosclerotic plaques [41] and associated with poor outcome after MI [42]. However, a common mutation in the MMP-3 promoter (which results in decreased MMP-3 expression) was associated with atherosclerosis development [43]

ACE2 levels were higher in patients with type 1 diabetes and coronary heart disease vs. controls [44]
No

No

\section{No}

Yes (higher in male vs.

female patients postMI [42])

Yes (conflicting data: Yes (higher in males vs. females with type 1 DM and females [45] or higher in male vs. female [44]) and CAD [44]) 
heart overexpresses ACE2 to protect itself against the deleterious effects of angiotensin II [52]. There is however conflicting data on sex differences in ACE2 expression. One study demonstrated similar ACE2 levels between healthy male and female subjects [45], while another study demonstrated that male controls had significantly higher ACE2 levels compared to females [44]. Although still significantly higher in male compared to female patients, the latter study demonstrated also that ACE2 was significantly higher in patients with type 1 diabetes and coronary heart disease compared to controls [44]. In line with this, a recent study in heart failure with reduced ejection fraction patients also showed that ACE2 was higher in male than female patients, independent of the use of pharmacological therapies targeting the renin-angiotensin-aldosterone system [53]. It is clear that further study to sex differences in ACE2 is warranted.

MMP-3 (or stromelysin-1) is an enzyme involved in the breakdown of extracellular matrix proteins and tissue remodeling in physiological (e.g., embryogenesis) and pathophysiological (e.g., tumor metastasis and atherosclerosis) processes [40]. High MMP-3 levels have been described in atherosclerotic plaques [41]. In contrast, a common mutation in the MMP-3 promoter (which results in decreased MMP-3 expression) was associated with atherosclerosis development [43]. Also, in patients with advanced dilated cardiomyopathy, MMP-3 levels were undetectable suggesting that lower levels are associated with worse cardiac function [54]. However, in a study of post-MI patients, MMP-3 levels were higher in male compared to female patients and higher MMP-3 levels were associated with poor outcome in MI [42]. In our study, we found that MMP-3 levels were higher in male than in female HFpEF patients. It is obvious that the exact role of MMP-3 remains unclear and warrants further investigation.

It must be noted that one of the circulating proteins that was excluded from the final selection because of being correlated to a different protein (PLIN1 in this case) was leptin. Leptin is a hormone that is released by adipocytes when they are overfilled with lipids, causing reduced food intake and increased energy expenditure [55]. It activates the sympathetic nervous system resulting in unfavorable neurohormonal changes such as an increase in blood pressure and cardiac hypertrophy [56]. A role in the pathophysiology of HFpEF was also suggested In HF patients (both HFrEF as HFpEF), and leptin levels were higher as compared to healthy controls [57]. Interestingly, the actions of leptin on the autonomic nervous system appear to be particularly marked in women [58]. In our study, female HFpEF patients had higher leptin levels compared to male patients. Although it has been previously hypothesized that leptin may play a role in the pathophysiology of HFpEF [59], the role of sex differences herein are not yet fully understood.

As can be appreciated above, for most of the circulating proteins that were differentially expressed between female and male HFpEF patients in our study, we could not find previous studies on sex differences. However, there have been reports on sex differences for some of the observed pathways. Body fat distribution is different between sexes where women have more subcutaneous and men more visceral fat. Visceral adiposity, as compared to subcutaneous adiposity, is associated with increased rates of lipolysis and inflammation, hence resulting in an increased susceptibility for metabolic complications (as reviewed in [60]). In HFpEF, it is hypothesized comorbidities such as diabetes and obesity induce a low-grade systemic pro-inflammatory state [61]. Whether sex differences in lipid metabolism are of importance in the pathophysiology of HFpEF warrants further investigation.

Moreover, there is an increasing body of evidence suggesting sex differences in primary and secondary hemostasis and fibrinolysis. It has been demonstrated, for example, that women have higher platelet counts and activity and generate more thrombin compared to men (as reviewed in [62]).

Lastly, sex differences in extracellular matrix turnover have also been previously reported. Women demonstrate a smaller fibrotic response compared to men as reflected by a lower expression of TGF-beta (a highly pro-fibrotic growth factor) in women (as reviewed in [63]). Moreover, in a mouse model, matrix metalloproteinase activity was higher in males compared to females after an acute MI, leading to poorer outcome in males [64]. Although cardiac fibrosis has been hypothesized by Paulus et al. to be one of the key players in the pathophysiology of HFpEF [61], the role of sex differences herein has yet to be identified. It is also possible that our finding of more activated extracellular matrix pathways in male compared to female HFpEF patients simply reflects the presence of more CAD in males (as observed in our study) and subsequent myocardial injury-induced extracellular matrix alterations.

\section{Sex differences: outcome}

Female sex was not associated with cardiovascular death and/or cardiovascular hospitalizations in our study. Our findings are in line with a recent post hoc analysis from PARAGON demonstrating similar rates of the composite of heart failure hospitalizations or death for cardiovascular reasons [65], but in conflict with previous other studies. Lam et al. observed in a post hoc analysis of IPRESERVE that female sex was associated with better prognosis, although the effect was moderated by 4 common baseline characteristics which were atrial 
fibrillation, renal dysfunction, stable angina pectoris, and NYHA class III/IV [20]. In the Meta-Analysis Global Group in Chronic Heart Failure (MAGGIC) metaanalysis, women had lower rates of all-cause mortality over 3 years compared to men, irrespective of ejection fraction [66]. Our findings and those of Lam et al. suggest that the relation between sex and outcome in HFpEF is confounded to some extent by comorbidities or other patient characteristics. Future studies need to determine whether a sex difference in prognosis exists.

\section{Perspectives and significance}

For the majority of the circulating proteins that were differently expressed between female and male HFpEF patients in our study, sex differences in a healthy population have not been studied. A recent populationbased study compared 30 cardiometabolic biomarkers (not including the proteins that were measured in MEDIA-DHF) between female and male participants and found that biomarker profiles significantly differed [67]. Whether the sex differences in circulating proteins in our cohort of HFpEF patients reflect pathophysiological or physiological processes warrants further study. Our findings of different pathways being activated in female compared to male HFpEF patients may be the basis of investigating therapies specifically targeting the identified pathways, potentially remediating the poor track record of past HFpEF large outcome trials [68]. In addition, they may be of help in the search for biologically plausible explanations for the sex differences in treatment response as reported for neprilysin inhibition [69], mineralocorticoid receptor antagonists [70], and cardiac resynchronization therapy [71].

\section{Limitations}

The most important limitation of this study is that we could not externally validate our findings due to the absence of other HFpEF cohorts in which similar proteins were measured. It is clear that other studies need to confirm our findings. Second, as already mentioned before, sex differences have not been studied in a general population for the majority of circulating proteins tested in our study. Moreover, in this study, only HFpEF patients were included and a "healthy" control group (including reference values for the measured proteins) was thus absent. It is therefore not clear whether the observed differences in biomarker expression reflect pathophysiological and/or physiological processes. Third, at the time of enrollment, HFpEF was diagnosed following 2007 ESC diagnostic recommendations. Since the 2007 criteria, other criteria have been proposed and it has recently been shown that large variations in the prevalence of diastolic dysfunction may be expected according to which criterion is used [72] However, when applying the $\mathrm{H}_{2}$ FPEF score by Reddy and colleagues [73] to the MEDIA-DHF cohort, only $2 \%$ of patients had a low probability of HFpEF, whereas $58 \%$ and $40 \%$ of patients had an intermediate or high probability, respectively. Fourth, although the biomarker assay in this study covers a wide variety of disease domains, the possibility exists that other, now unmeasured, proteins may (also) play a role in the pathophysiology of HFpEF. Fifth, the biomarker assay does not provide standard concentration units, making comparisons with clinically applied cut-offs difficult.

\section{Conclusion}

Assessing sex differences in $>400$ circulating proteins analyzed in a large cohort of HFpEF patients led to the identification of 9 uncorrelated sex-specific proteins. Females expressed more markers associated with lipid metabolism, transcriptional regulation, and hemostasis, whereas they expressed less proteins associated with extracellular matrix organization and developmental processes. These findings may help further investigations into potential pathophysiological processes contributing to HFpEF.

\section{Supplementary information}

Supplementary information accompanies this paper at https://doi.org/10. 1186/s13293-020-00322-7.

Additional file 1: Supplemental data. Table S1-S3.

Additional file 2. Flowchart of patients included in the study

\section{Acknowledgements}

We thank other colleagues for their important contributions to the MEDIA study in the participating centers, including the CRB Lorrain for the biobanking, Gabor Kunszt (Oslo University Hospital), Tamas Erdei, and Julie Edwards (Cardiff University).

\section{Authors' contributions}

SS analyzed and interpreted the data and drafted the manuscript. JPF made substantial contributions to the design and analysis, and drafting of the manuscript. MK analyzed the data and revised the manuscript. DD made substantial contributions to the conception of the data and revised the manuscript. GP, JLM, and KD developed the software used for the analysis and revised the manuscript. KD developed the software used for the analysis and revised the manuscript. EB and MDD performed the complex network analyses and revised the manuscript. NLA helped interpreting the data and revised the manuscript. SA, GA, HFBLR, RFC, AF, LvH, GdK, PM, KM, AM, ZP, $R R, C T$, and WJP made substantial contributions to the conception of the data and revised the manuscript. NG, FZ, and PR made substantial contributions to the conception of the data, the design of the study, and substantial revisions to the manuscript. All authors have approved the submitted version and both to be personally accountable for the author's own contributions and to ensure that questions related to the accuracy or integrity of any part of the work, even ones in which the author was not personally involved, are appropriately investigated, resolved, and the resolution documented in the literature.

\section{Availability of data and materials}

The data that support the findings of this study are available from the corresponding author upon reasonable request.

\section{Ethics approval and consent to participate}

The study protocol complied with the Declaration of Helsinki and was approved by the respective Ethics Committees of the participating 
institutions. Written informed consent was provided by all patients (ClinicalTrials.gov identifier: NCT02446327).

\section{Consent for publication}

Not applicable

\section{Competing interests}

This study was supported by a grant from the European Union (FP7-HEALTH2010-MEDIA), by the French Programme Hospitalier de Recherche Clinique (PHRC), and by the RHU Fight-HF, a public grant overseen by the French National Research Agency (ANR) as part of the second "Investissements d'Avenir" program (reference: ANR-15-RHU-0004), the GEENAGE (ANR-15-IDEX-04LUE) program, by the Contrat de Plan Etat Région Lorraine and FEDER IT2MP. N-LA was supported by a Miguel Servet contract CP13/00221 from the "Instituto de Salud Carlos III-FEDER". WJP and LVH were supported by CVON, Dutch Heart Foundation, The Hague, The Netherlands (RECONNECT and EARLY-HFpEF projects). AM received speaker's honoraria from Orion, Otsuka, Philips, Roche, and Servier. AM received fees as a member of the advisory board and/or Steering Committee and/or research grant from Adrenomed, Epygon, Neurotronik, Roche, Sanofi, and Sphyngotec. AM owns shares in SForm Pharma. SS acknowledges funding received from the European Society of Cardiology in the form of an ESC Research Grant (R-2018-18686).

\section{Author details}

'Université de Lorraine, INSERM, Centre d'Investigation Clinique et Plurithématique 1433, INSERM U1116, CHRU de Nancy, F-CRIN INI-CRCT (Cardiovascular and Renal Clinical Trialists), Nancy, France. ${ }^{2}$ Department of Physiology and Cardiothoracic Surgery, Cardiovascular Research and Development Unit, Faculty of Medicine, University of Porto, Porto, Portugal. ${ }^{3}$ Clinical Research and Investigation Unit, Psychotherapeutic Center of Nancy, Laxou, France. ${ }^{4}$ LORIA (CNRS, Inria NGE, Université de Lorraine), Campus Scientifique, F-54506 Vandœuvre-lès-Nancy, France. ${ }^{5}$ Navarrabiomed, Complejo Hospitalario de Navarra (CHN), Universidad Pública de Navarra (UPNA), IdiSNA, Pamplona, Spain. ${ }^{6}$ Oslo University Hospital, Oslo, Norway. ${ }^{7}$ ISB, Norwegian University of Science and Technology, Trondheim, Norway. ${ }^{8}$ Division of Cardiology, University of Perugia School of Medicine, Perugia, Italy. ${ }^{9}$ Department of Cardiology, Maastricht University Medical Center, Maastricht, the Netherlands. ${ }^{10}$ Department of Surgery and Physiology, Cardiovascular Research Unit (UnIC), Faculty of Medicine, University of Porto, Porto, Portugal. ${ }^{11}$ Wales Heart Research Institute, Cardiff University, Cardiff, UK. ${ }^{12}$ Department of Cardiology, Onze Lieve Vrouwe Gasthuis, Amsterdam, the Netherlands. ${ }^{13}$ Laboratory of Physiopharmacology, Antwerp University and ZNA Hartcentrum, Antwerp, Belgium. ${ }^{14}$ Clinical Cardiology, Università del Piemonte Orientale, Department of Translational Medicine, Azienda Ospedaliero Universitaria "Maggiore della Carità", Novara, Italy. ${ }^{15}$ St Michael's Hospital Dun Laoghaire Co. Dublin, Dublin, Ireland. ${ }^{16}$ Department of Anaesthesiology and Critical Care Medicine, Saint Louis and Lariboisière University Hospitals and INSERM UMR-S 942, Paris, France. ${ }^{17}$ Division of Clinical Physiology, Department of Cardiology, Faculty of Medicine, University of Debrecen, Debrecen, Hungary. ${ }^{18}$ Department of Cardiology, Spedali Civili di Brescia, Brescia, Italy. ${ }^{19}$ Department of Cardiology, Campus Virchow-Klinikum, Charite Universitaetsmedizin Berlin, Berlin Institute of Health - Center for Regenerative Therapies (BIH-BCRT), and the German Center for Cardiovascular Research (DZHK ; Berlin partner site), Berlin, Germany. ${ }^{20}$ Amsterdam Cardiovascular Sciences, Amsterdam University Medical Centers, Amsterdam, the Netherlands.

\section{Received: 9 March 2020 Accepted: 17 July 2020}

Published online: 24 August 2020

\section{References}

1. Meta-analysis global group in chronic heart failure (MAGGIC). The survival of patients with heart failure with preserved or reduced left ventricular ejection fraction: an individual patient data meta-analysis. Eur Heart J. 2012; 33(14):1750-7.

2. Dunlay SM, Roger VL, Redfield MM. Epidemiology of heart failure with preserved ejection fraction. Nat Rev Cardiol. 2017;14(10):591-602.

3. Ponikowski P, Voors AA, Anker SD, Bueno H, Cleland JGF, Coats AJS, et al. 2016 ESC Guidelines for the diagnosis and treatment of acute and chronic heart failure: The Task Force for the diagnosis and treatment of acute and chronic heart failure of the European Society of Cardiology (ESC)Developed with the special contribution of the Heart Failure Association (HFA) of the ESC. Eur Heart J. 2016;37(27):2129-200.

4. Tsao CW, Lyass A, Enserro D, Larson MG, Ho JE, Kizer JR, et al. Temporal Trends in the Incidence of and Mortality Associated With Heart Failure With Preserved and Reduced Ejection Fraction. JACC Heart failure. 2018;6(8):678-85.

5. Ho JE, Gona P, Pencina MJ, Tu JV, Austin PC, Vasan RS, et al. Discriminating clinical features of heart failure with preserved vs. reduced ejection fraction in the community. Eur Heart J. 2012;33(14):1734-41.

6. Beale AL, Meyer P, Marwick TH, Lam CSP, Kaye DM. Sex Differences in Cardiovascular Pathophysiology: Why Women Are Overrepresented in Heart Failure With Preserved Ejection Fraction. Circulation. 2018;138(2):198-205.

7. Stienen S, Ferreira JP, Kobayashi M, Preud'homme G, Dobre D, Machu $J$, et al. Enhanced clinical phenotyping by mechanistic bioprofiling in heart failure with preserved ejection fraction: insights from the MEDIADHF study (The Metabolic Road to Diastolic Heart Failure). Biomarkers. 2020;25(2):201-11.

8. Paulus WJ, Tschope C, Sanderson JE, Rusconi C, Flachskampf FA, Rademakers FE, et al. How to diagnose diastolic heart failure: a consensus statement on the diagnosis of heart failure with normal left ventricular ejection fraction by the Heart Failure and Echocardiography Associations of the European Society of Cardiology. Eur Heart J. 2007;28(20):2539-50.

9. Assarsson E, Lundberg M, Holmquist G, Bjorkesten J, Thorsen SB, Ekman D, et al. Homogenous 96-plex PEA immunoassay exhibiting high sensitivity, specificity, and excellent scalability. PLoS One. 2014;9(4):e95192.

10. UniProt: the universal protein knowledgebase. Nucleic acids research. 2017; 45(D1):D158-d69.

11. Kibbe WA, Arze C, Felix V, Mitraka E, Bolton E, Fu G, et al. Disease Ontology 2015 update: an expanded and updated database of human diseases for linking biomedical knowledge through disease data. Nucleic Acids Res. 2015;43(Database issue):D1071-8.

12. Pinero J, Bravo A, Queralt-Rosinach N, Gutierrez-Sacristan A, Deu-Pons J, Centeno E, et al. DisGeNET: a comprehensive platform integrating information on human disease-associated genes and variants. Nucleic Acids Res. 2017;45(D1):D833-d9.

13. Fabregat A, Jupe S, Matthews L, Sidiropoulos K, Gillespie M, Garapati P, et al. The Reactome Pathway Knowledgebase. Nucleic Acids Res. 2018;46(D1):D649-d55.

14. Szklarczyk D, Franceschini A, Wyder S, Forslund K, Heller D, Huerta-Cepas J, et al. STRING v10: protein-protein interaction networks, integrated over the tree of life. Nucleic Acids Res. 2015;43(Database issue):D447-52.

15. Slenter DN, Kutmon M, Hanspers K, Riutta A, Windsor J, Nunes N, et al. WikiPathways: a multifaceted pathway database bridging metabolomics to other omics research. Nucleic Acids Res. 2018;46(D1):D661-d7.

16. Calderone A, Castagnoli L, Cesareni G. mentha: a resource for browsing integrated protein-interaction networks. Nat Methods. 2013;10(8):690-1.

17. Chatr-Aryamontri A, Oughtred R, Boucher L, Rust J, Chang C, Kolas NK, et al. The BioGRID interaction database: 2017 update. Nucleic Acids Res. 2017; 45(D1):D369-d79.

18. Rubin DB. Multiple Imputation for Nonresponse in Surveys. New York: John Wiley and Sons; 2004

19. Goyal P, Paul T, Almarzooq ZI, Peterson JC, Krishnan U, Swaminathan RV, et al. Sex- and Race-Related Differences in Characteristics and Outcomes of Hospitalizations for Heart Failure With Preserved Ejection Fraction. J Am Heart Assoc. 2017;6:4.

20. Lam CS, Carson PE, Anand IS, Rector TS, Kuskowski M, Komajda M, et al. Sex differences in clinical characteristics and outcomes in elderly patients with heart failure and preserved ejection fraction: the Irbesartan in Heart Failure with Preserved Ejection Fraction (I-PRESERVE) trial. Circ Heart Fail. 2012;5(5): 571-8.

21. Spinarova L, Spinar J, Vitovec J, Linhart A, Widimsky P, Fedorco M, et al. Gender differences in total cholesterol levels in patients with acute heart failure and its importance for short and long time prognosis. Biomedical papers of the Medical Faculty of the University Palacky, Olomouc, Czechoslovakia. 2012;156(1):21-8.

22. Merz AA, Cheng S. Sex differences in cardiovascular ageing. Heart. 2016; 102(11):825-31.

23. Walsh PT, Fallon PG. The emergence of the IL-36 cytokine family as novel targets for inflammatory diseases. Ann N Y Acad Sci. 2018;1417(1):23-34.

24. Chiu AP, Wan A, Rodrigues B. Cardiomyocyte-endothelial cell control of lipoprotein lipase. Biochim Biophys Acta. 2016;1861(10):1434-41.

25. He PP, Jiang T, OuYang XP, Liang YQ, Zou JQ, Wang Y, et al. Lipoprotein lipase: Biosynthesis, regulatory factors, and its role in atherosclerosis and 
other diseases. Clinica chimica acta; international journal of clinical chemistry. 2018;480:126-37.

26. He H, Yang F, Liu X, Zeng X, Hu Q, Zhu Q, et al. Sex hormone ratio changes in men and postmenopausal women with coronary artery disease. Menopause (New York, NY). 2007;14(3 Pt 1):385-390.

27. Baxter RC. IGF binding proteins in cancer: mechanistic and clinical insights. Nat Rev Cancer. 2014;14(5):329-41.

28. Bayes-Genis A, Conover CA, Schwartz RS. The insulin-like growth factor axis: A review of atherosclerosis and restenosis. Circ Res. 2000;86(2):125-30.

29. Bruno C, Silvestrini A, Calarco R, Favuzzi AMR, Vergani E, Nicolazzi MA, et al. Anabolic Hormones Deficiencies in Heart Failure With Preserved Ejection Fraction: Prevalence and Impact on Antioxidants Levels and Myocardial Dysfunction. Front Endocrinol (Lausanne). 2020;11:281.

30. Lee WL, Chen JW, Ting CT, Lin SJ, Wang PH. Changes of the insulin-like growth factor I system during acute myocardial infarction: implications on left ventricular remodeling. J Clin Endocrinol Metab. 1999;84(5):1575-81.

31. Aneke-Nash CS, Xue X, Qi Q, Biggs ML, Cappola A, Kuller L, et al. The Association Between IGF-I and IGFBP-3 and Incident Diabetes in an Older Population of Men and Women in the Cardiovascular Health Study. J Clin Endocrinol Metab. 2017;102(12):4541-7.

32. Greenberg AS, Egan JJ, Wek SA, Garty NB, Blanchette-Mackie EJ, Londos C. Perilipin, a major hormonally regulated adipocyte-specific phosphoprotein associated with the periphery of lipid storage droplets. J Biol Chem. 1991; 266(17):11341-6

33. Zhang $P$, Meng L, Song L, Du J, Du S, Cui W, et al. Roles of Perilipins in Diseases and Cancers. Current genomics. 2018;19(4):247-57.

34. Mazzali G, Fantin F, Zoico E, Sepe A, Bambace C, Faccioli S, et al. Heart Fat Infiltration In Subjects With and Without Coronary Artery Disease. J Clin Endocrinol Metab. 2015;100(9):3364-71.

35. Huang L, Yang Y, Yang F, Liu S, Zhu Z, Lei Z, et al. Functions of EpCAM in physiological processes and diseases (Review). Int J Mol Med. 2018;42(4): 1771-85.

36. Bouwens E, van den Berg VJ, Akkerhuis KM, Baart SJ, Caliskan K, Brugts JJ, et al. Circulating Biomarkers of Cell Adhesion Predict Clinical Outcome in Patients with Chronic Heart Failure. J Clin Med. 2020;9:1.

37. Zachary I. Neuropilins: role in signalling, angiogenesis and disease. Chemical immunology and allergy. 2014;99:37-70.

38. Geretti E, Shimizu A, Klagsbrun M. Neuropilin structure governs VEGF and semaphorin binding and regulates angiogenesis. Angiogenesis. 2008;11(1):31-9.

39. Tromp J, Khan MA, Klip IT, Meyer S, de Boer RA, Jaarsma T, et al. Biomarker profiles in heart failure patients with preserved and reduced ejection fraction. J Am Heart Assoc. 2017;6:4.

40. DeLeon-Pennell KY, Meschiari CA, Jung M, Lindsey ML. Matrix metalloproteinases in myocardial infarction and heart failure. Prog Mol Bio Transl Sci. 2017:147:75-100.

41. Galis ZS, Sukhova GK, Lark MW, Libby P. Increased expression of matrix metalloproteinases and matrix degrading activity in vulnerable regions of human atherosclerotic plaques. J Clin Invest. 1994;94(6):2493-503.

42. Kelly D, Khan S, Cockerill G, Ng LL, Thompson M, Samani NJ, et al. Circulating stromelysin-1 (MMP-3): a novel predictor of LV dysfunction, remodelling and all-cause mortality after acute myocardial infarction. Eur J Heart Fail. 2008;10(2):133-9.

43. Humphries S, Bauters C, Meirhaeghe A, Luong L, Bertrand M, Amouyel P. The 5A6A polymorphism in the promoter of the stromelysin-1 (MMP3) gene as a risk factor for restenosis. Eur Heart J. 2002;23(9):721-5.

44. Soro-Paavonen A, Gordin D, Forsblom C, Rosengard-Barlund M, Waden J, Thorn L, et al. Circulating ACE2 activity is increased in patients with type 1 diabetes and vascular complications. J Hypertens. 2012;30(2):375-83.

45. Fernandez-Atucha A, Izagirre A, Fraile-Bermudez AB, Kortajarena M, Larrinaga $G$, Martinez-Lage $P$, et al. Sex differences in the aging pattern of renin-angiotensin system serum peptidases. Biol Sex Differ. 2017:8:5.

46. Voshol PJ, Rensen PC, van Dijk KW, Romijn JA, Havekes LM. Effect of plasma triglyceride metabolism on lipid storage in adipose tissue: studies using genetically engineered mouse models. Biochim Biophys Acta. 2009;1791(6): 479-85.

47. Okubo M, Horinishi A, Saito M, Ebara T, Endo Y, Kaku K, et al. A novel complex deletion-insertion mutation mediated by Alu repetitive elements leads to lipoprotein lipase deficiency. Mol Genet Metab. 2007:92(3):229-33.

48. Ferreira LD, Pulawa LK, Jensen DR, Eckel RH. Overexpressing human lipoprotein lipase in mouse skeletal muscle is associated with insulin resistance. Diabetes. 2001;50(5):1064-8.
49. Delezie J, Dumont S, Dardente H, Oudart H, Gréchez-Cassiau A, Klosen P, et al. The nuclear receptor REV-ERBa is required for the daily balance of carbohydrate and lipid metabolism. FASEB J. 2012;26(8):3321-35.

50. Liu S, Geng B, Zou L, Wei S, Wang W, Deng J, et al. Development of hypertrophic cardiomyopathy in perilipin-1 null mice with adipose tissue dysfunction. Cardiovasc Res. 2015;105(1):20-30.

51. Li F, Zhao H, Liao Y, Takashima S, Asano Y, Shintani Y, et al. Higher mortality in heterozygous neuropilin-1 mice after cardiac pressure overload. Biochem Biophys Res Commun. 2008;370(2):317-21.

52. Kittana N. Angiotensin-converting enzyme 2-Angiotensin 1-7/1-9 system: novel promising targets for heart failure treatment. Fundam Clin Pharmacol. 2018;32(1):14-25.

53. Sama IE, Ravera A, Santema BT, van Goor H, Ter Maaten JM, Cleland JGF, et al. Circulating plasma concentrations of angiotensin-converting enzyme 2 in men and women with heart failure and effects of renin-angiotensinaldosterone inhibitors. Eur Heart J. 2020;41(19):1810-7.

54. Felkin LE, Birks EJ, George R, Wong S, Khaghani A, Yacoub MH, et al. A quantitative gene expression profile of matrix metalloproteinases (MMPS) and their inhibitors (TIMPS) in the myocardium of patients with deteriorating heart failure requiring left ventricular assist device support. The Journal of heart and lung transplantation : the official publication of the International Society for Heart Transplantation. 2006;25(12):1413-9.

55. Pandit R, Beerens S, Adan RAH. Role of leptin in energy expenditure: the hypothalamic perspective. Am J Phys Regul Integr Comp Phys. 2017;312(6): R938-R47.

56. Schwartz MW, Seeley RJ, Campfield LA, Burn P, Baskin DG. Identification of targets of leptin action in rat hypothalamus. J Clin Invest. 1996:98(5):1101-6.

57. Faxén UL, Hage C, Andreasson A, Donal E, Daubert JC, Linde C, et al. HFpEF and HFrEF exhibit different phenotypes as assessed by leptin and adiponectin. Int J Cardiol. 2017;228:709-16.

58. Flanagan DE, Vaile JC, Petley GW, Phillips DI, Godsland IF, Owens P, et al. Gender differences in the relationship between leptin, insulin resistance and the autonomic nervous system. Regul Pept. 2007;140(1-2):37-42.

59. Packer M. Leptin-aldosterone-neprilysin axis: identification of its distinctive role in the pathogenesis of the three phenotypes of heart failure in people with obesity. Circulation. 2018;137(15):1614-31.

60. Chang E, Varghese M, Singer K. Gender and sex differences in adipose tissue. Curr Diab Rep. 2018;18(9):69.

61. Paulus WJ, Tschöpe C. A novel paradigm for heart failure with preserved ejection fraction: comorbidities drive myocardial dysfunction and remodeling through coronary microvascular endothelial inflammation. J Am Coll Cardiol. 2013;62(4):263-71.

62. Hvas AM, Favaloro EJ. Gender related issues in thrombosis and hemostasis. Expert Rev Hematol. 2017;10(11):941-9.

63. Kessler EL, Rivaud MR, Vos MA, van Veen TAB. Sex-specific influence on cardiac structural remodeling and therapy in cardiovascular disease. Biol Sex Differ. 2019:10(1):7.

64. Cavasin MA, Tao Z, Menon S, Yang XP. Gender differences in cardiac function during early remodeling after acute myocardial infarction in mice. Life Sci. 2004;75(18):2181-92.

65. McMurray JJV, Jackson AM, Lam CSP, Redfield MM, Anand IS, Ge J, et al. Effects of sacubitril-valsartan, versus valsartan, in women compared to men with heart failure and preserved ejection fraction: Insights from PARAGONHF. Circulation. 2019.

66. Martinez-Selles M, Doughty RN, Poppe K, Whalley GA, Earle N, Tribouilloy C, et al. Gender and survival in patients with heart failure: interactions with diabetes and aetiology. Results from the MAGGIC individual patient metaanalysis. Eur J Heart Fail. 2012;14(5):473-9.

67. Lew J, Sanghavi M, Ayers CR, McGuire DK, Omland T, Atzler D, et al. Sex-based differences in cardiometabolic biomarkers. Circulation. 2017;135(6):544-55.

68. Rossignol P, Hernandez AF, Solomon S, Zannad F. Heart failure drug treatment. Lancet. 2019;in press.

69. Solomon SD, McMurray JJV, Anand IS, Ge J, Lam CSP, Maggioni AP, et al. Angiotensin-neprilysin inhibition in heart failure with preserved ejection fraction. N Engl J Med. 2019;381(17):1609-20.

70. Solomon SD, Claggett B, Lewis EF, Desai A, Anand I, Sweitzer NK, et al. Influence of ejection fraction on outcomes and efficacy of spironolactone in patients with heart failure with preserved ejection fraction. Eur Heart J. 2016;37(5):455-62

71. Linde C, Cleland JGF, Gold MR, Claude Daubert J, Tang ASL, Young JB, et al. The interaction of sex, height, and QRS duration on the effects of cardiac 
resynchronization therapy on morbidity and mortality: an individual-patient data meta-analysis. Eur J Heart Fail. 2018;20(4):780-91.

72. Huttin O, Fraser AG, Coiro S, Bozec E, Selton-Suty C, Lamiral Z, et al. Impact of changes in consensus diagnostic recommendations on the echocardiographic prevalence of diastolic dysfunction. J Am Coll Cardiol. 2017:69(25):3119-21.

73. Reddy YNV, Carter RE, Obokata M, Redfield MM, Borlaug BA. A simple, evidence-based approach to help guide diagnosis of heart failure with preserved ejection fraction. Circulation. 2018;138(9):861-70.

\section{Publisher's Note}

Springer Nature remains neutral with regard to jurisdictional claims in published maps and institutional affiliations.

Ready to submit your research? Choose BMC and benefit from:

- fast, convenient online submission

- thorough peer review by experienced researchers in your field

- rapid publication on acceptance

- support for research data, including large and complex data types

- gold Open Access which fosters wider collaboration and increased citations

- maximum visibility for your research: over $100 \mathrm{M}$ website views per year

At $\mathrm{BMC}$, research is always in progress.

Learn more biomedcentral.com/submissions 